\title{
G Protein-coupled Receptors: One of the Most Important Drug Discovery Targets
}

\author{
Yusra Saleh H. Andijani, Pharm.D, Msc. \\ Department of Pharmacology and Toxicology \\ Taibah University, Madinah, Saudi Arabia
}

\section{Correspondence}

Ms. Yusra Saleh H. Andijani

College of Pharmacy, Taibah University

Prince Nayef Road, P.O. Box 344,

Al-Madinah Al-Munawarah 42353

Saudi Arabia

e.M: yandijani@taibahu.edu.sa

\section{Submission: 12 Sept. 2018 \\ Accepted: 13 Nov. 2018}

\section{Citation}

Andijani YHSH. G-protein coupled receptors: one of the most important drug discovery targets. JKAU Med Sci 2018; 25 (2): 27-35. DOI: 10.4197/Med. 25.2.3

Copyright: @The Author(s), YEAR. Publisher. The Journal of King Abdualziz University - Medical Sciences is an Official Publication of "King Abdulaziz University". It is an open-access article distributed under the terms of the Creative Commons Attribution Non-Commercial License, which permit unrestricted non-commercial use, distribution, and reproduction in any medium, provided the original work is properly cited.

\begin{abstract}
$\mathrm{G}$ protein-coupled receptors are considered the most widely investigated drug discovery targets. They are the largest family of receptors with almost 800 genes in humans. Different types of ligands can activate these receptors, such as catecholamines, nucleotides, lipids, and gut microbiota, where some ligands could be bitopic. Nevertheless, some receptors have internal ligands bound to them. Activated $G$ protein-coupled receptors have complex signaling pathways that are involved in almost all bodily functions. Furthermore, they constitute a large percentage of Food and Drug Administration marketed drugs and global share of drugs, in addition to a great proportion of drugs currently in clinical trials targeting these receptors. The approved $\mathrm{G}$ protein-coupled receptors targeted drugs and potential drugs are involved in the management of many diseases including cancer, inflammatory diseases, diabetes mellitus, hypertension, obesity, pain, and diseases of the central nervous system. On the other hand, only $10 \%$ of $\mathrm{G}$ protein-coupled receptors are targeted. Different pharmacological approaches have been considered in drug discovery of these receptors including polypharmacology, allosteric modulators, biased agonism, tethered agonism, and pharmacogenomics. Advances in the technologies are promising to help in the discovery of new targets. Thus, the aim of this review is to discuss the importance of $\mathrm{G}$ protein-coupled receptors as drug discovery targets.
\end{abstract}

\section{Keywords}

G protein-coupled receptors; Drug discovery; Targets

\section{Introduction}

\footnotetext{
G
} protein-coupled receptors (GPCRs), which are also named seven-transmembrane receptors (7TM), heptahelical receptors, and serpentine receptors, are the largest family of receptors. More than 800 GPCRs genes are in the human genome accounting for nearly $3.4 \%$ of the total predicted protein coded genes ${ }^{[2,3]}$. Of these 800 members, around 400 are olfactory receptors, receptors mainly for smell and taste. The olfactory receptors are well recognized to be expressed in a variety of cells all over the body as well as in tumor cells ${ }^{[4]}$. However, most of the non-olfactory receptors have not been identified as drug targets ${ }^{[5]}$. Considering the process of post-translational modification, the number of these receptors could be increased. For instance, post-translational modification by ribonucleic acid (RNA) editing and alternative splicing of premessenger ribonucleic acid (mRNA) ${ }^{[2]}$. 
Nearly 34\% of Food and Drug Administration -marketed drugs, 475 drugs, for management of common illnesses target GPCRs ${ }^{[3]}$; in addition to $27 \%$ of the international market share of drugs accounted by GPCRs sales ${ }^{[6]}$. However, current drugs target only $10 \%$ of GPCRs in human genome, nearly 80 known receptors are targeted ${ }^{[7]}$. Therefore, it is projected that the area of GPCRs drug discovery targets are yet to be revealed even though they are the targets of the most marketed drugs.

Recently, drug discovery targets in GPCRs have been developed. More than 60 drugs targeting GPCRs have been approved by the Food \& Drug Administration $(U S)^{[3]}$. For example, etelcalcetide, a positive allosteric modulator to calcium-sensing receptors (CaSRs), used in the treatment of secondary hyperparathyroidism ${ }^{[8]}$.

In current clinical trials, there are 321 GPCRs targeted drugs, with 60 drugs targeting new GPCRs that do not have current approved drugs ${ }^{[3]}$. The FDA approved drugs acting on GPCRs mediate their actions via 108 GPCRs, which accounts for $27 \%$ of the human non-olfactory GPCRs. Drug targets for amine receptors are all known, where they are targeted by 314 of the approved drugs. Each known GPCR target is used by an average of $10.3 \mathrm{drugs}^{[3]}$. The previous findings indicate the need for the discovery of new targets of GPCRs and novel drugs targeting them. Therefore, the aim of this review is to discuss GPCRs as significant drug discovery targets.

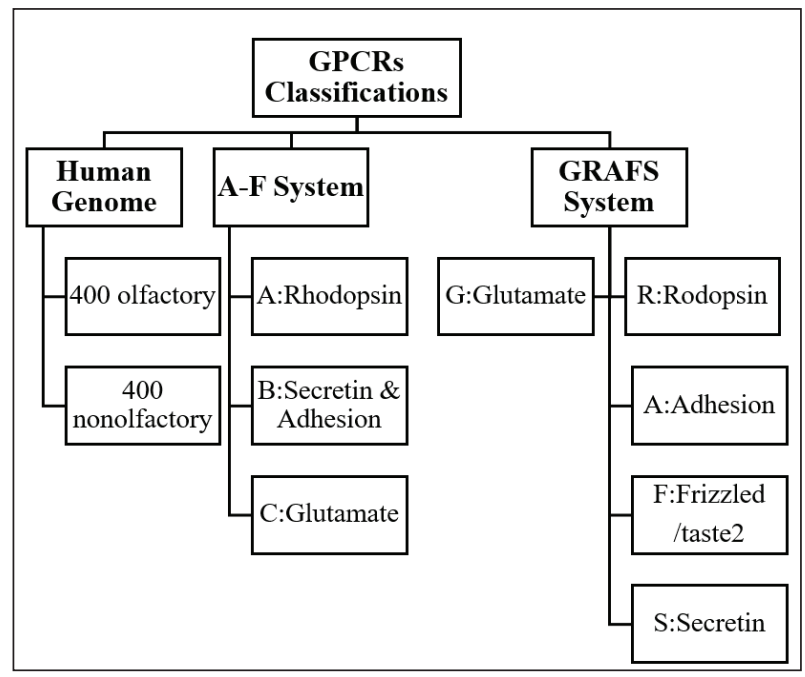

Figure 1. The most common classifications of GPCRs.

\section{GPCRs Classifications}

There are several classifications for GPCRs (Fig. 1). According to the approximately 800 members in the human genome, GPCRs are classified as 400 olfactory and 400 nonolfactory receptors. The most commonly used classification is the one that categorizes GPCRs into six classes, class A to F, A-F system. Nevertheless, class $D$ and $E$ are not in the human genome. $G$ proteincoupled receptors class A (rhodopsin family), the major family in which ligands bind to the 7TM. On the other hand, GPCRs class B (secretin and adhesion receptor family) is a smaller family than class $A$, where the extracellular $\mathrm{N}$-terminus region is the ligand binding site $^{[2,9,10]}$.

On the other hand, GPCRs class C (glutamate receptor family) is the smallest family that is presented as constitutive dimers, has a venus flytrap domain in the N-terminus, where this domain closes upon ligand binding. Metabotropic glutamate receptors, CaSRs, Gamma aminobutyric acid B (GABA B) receptors, and sweet and umami taste receptors are all GPCRs class $C$. GRAFS classification system classifies GPCRs into five families, where each letter stands for: Glutamate $(G)$, Rhodopsin (R), Adhesion (A), Frizzled/taste2 (F), and Secretin $(S)^{[2,9,10]}$.

\section{GPCRs Ligands}

A variety of ligands can activate GPCRs, where one ligand can activate many receptor subtypes. These ligands include catecholamines, biogenetic amines such as histamine, nucleotides, peptides such as bradykinin, lipids such as prostaglandin and leukotrienes, and glycoprotein hormones such as thyrotropin. In addition, photons can activate GPCRs through rhodopsin, which is the light-sensing receptors in the retina ${ }^{[2]}$. Nevertheless, endogenous ligands for around 120 orphan GPCRs are yet to be identified ${ }^{[2,11]}$.

\section{Bitopic Ligands}

Another type of GPCRs ligands is called bitopic ligands or dualsteric ligands. As the name implies, bitopic ligands are ligands acting on both orthostatic and allosteric sites of the same receptors ${ }^{[12]}$. Increasing affinity of the targeted GPCR, enhancing selectivity on the receptors or on the signaling pathway are proposed advantages of bitopic ligands. Furthermore, the binding of bitopic ligands to orthostatic sites does not 
depend on endogenous ligands tone as the binding of orthostatic ligands does ${ }^{[12]}$.

A novel bitopic antagonist, SPM-242, has been identified acting on Sphingosine 1-phosphate receptor $^{[13]}$. Sphingosine 1-phosphate receptor is a GPCR that has been involved in sepsis and cancer, where it could be targeted to treat these condition $s^{[14]}$.

\section{Gut Microbiota as Ligands for GPCRs}

The presence of gut microbiota has been known to protect the health of individuals, such as maintaining gut integrity, defensing against pathogens, improving the immunity, metabolizing food, and synthesizing vitamins, such as vitamin $\mathrm{B} 12^{[15]}$. Consequently, disturbance of gut microbiota, dysbiosis, has been implicated in the pathogenesis of illnesses. For instance, studies proposed that the disturbance of gut microbiota is associated with the development of Alzheimer's disease ${ }^{[16]}$.

Several commensal bacteria effector genes encoding proteins involved in ligand binding, anabolism, and catabolism have been identified. An agonist, commendamide, at proton-sensing GPCR, lysophosphatidylcholine (LPC) receptors (G2A) GRP132) from Cbeg12 gene family has been discovered. $\mathrm{G} 2 \mathrm{~A}$ has been associated with atherosclerosis and autoimmunity, where ligands acting on GPCR G2A/ GRP132 could be future targets to treat these conditions $^{[17]}$.

\section{GPCRs Signaling}

G protein-coupled receptors detect an extracellular signal and initiates a signal transduction cascade (Fig. 2) that leads to cellular responses. The classical signaling pathway is through the interaction with heterotrimeric guanine nucleotide-binding protein (G-protein). Ligand binding activates GPCRs to interact with G-protein. Nonetheless, rhodopsin, the lightactive receptors and proteinase-activated receptors (PARs) are activated by a photon of light and a protease agonist, respectively. A photon of light causes G-protein coupling with the receptors while a protease agonist cleaves the $\mathrm{N}$-terminus, which acts as a tethered agonist interacting with the second loop and activating the receptor ${ }^{[2,9]}$. In other words, the ligands of rhodopsin and PARs are already bound to them by a covalent bond, where light and protease activate them to interact with the receptors ${ }^{[18]}$. This phenomenon is called tethered agonism, which will be defined in this article.

A newer signaling mechanism of GPCRs involves $\beta$-arrestin. This type of signaling is recognized as $\beta$-arrestin-G-protein coupled receptor kinases signaling ( $\beta$-arrestin-GRK signaling), where seven types of GRKs were identified. $G$ protein-coupled receptor kinase causes phosphorylation of the activated GPCR that leads to $\beta$-arrestin-receptor interaction, which results in desensitization, internalization of the receptor, or signaling. Mitogen-activated protein kinase (MAPK) is the most widely studied pathway in $\beta$-arrestin-GRK signaling, where phosphorylation of GPCR by GRK causes interaction of $\beta$-arrestin with the receptor. $\beta$-arrestin-receptor complex activates MAPKs that leads to recruitment of Src, Akt, and other proteins, which results in different cellular responses ${ }^{[19]}$.

\section{GPCRs Physiological and Pathophysiological Effects}

$\mathrm{G}$ protein-coupled receptors regulate a variety of physiological processes through activation of heterotrimeric G-protein, which consists of alpha(a), beta $(\beta)$ and gamma( $\gamma)$ subunits, with GDP (inactive form) or GTP (active form) binding to the a subunit. In human genome, there are $21 \mathrm{Ga}, 6 \mathrm{G} \beta$ and $12 \mathrm{G} \gamma$ known subunits. The main families of $G$ a subunit with their effectors are illustrated in Table 1. Several regulators of G-proteins activity have been identified including

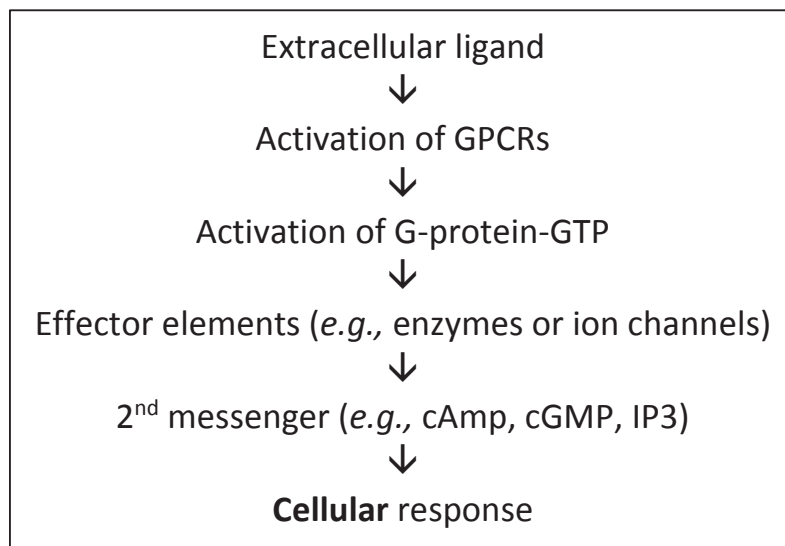

CAMP = cyclic adenosine monophosphate CGMP = cyclic guanosine monophosphate IP3 = inositol 1,4,5-trisphosphate

GTP = Guanosine triphosphate

Figure 2. Signal transduction through GPCRs G-Protein interaction. 
GPCRs: Drug Discovery Targets

Y.S.H. Andijani

Table 1. The main families of Ga subunit with their effectors.

\begin{tabular}{|c|l|l|l|}
\hline Subunit & \multicolumn{1}{|c|}{ Family } & \multicolumn{1}{|c|}{ Effector } & \multicolumn{1}{|c|}{ Pathway } \\
\hline $\mathrm{G} \alpha$ & $\mathrm{Gs}$ & -Activates adenylyl cyclase & -Increase cAMP \\
\hline & $\mathrm{Gi} / 0$ & -Inhibits adenylyl cyclase & -Decrease cAMP \\
\hline & $\mathrm{Gq}$ & -Activates Phospholipase C & -IP3, DAG, cytoplasmic Ca2+concentration \\
\hline & $\mathrm{G} 12 / 13$ & -GEFs for monomeric G- protein such as RhoA. & -Muscle contraction, cell migration, cell adhesion, angiogenesis. \\
\hline
\end{tabular}

CAMP: Cyclic Adenosine Monophosphate, DAG: Diacylglycerol, GEFs: Guanine nucleotide exchange factors,

IP3: Inositol triphosphate, RhoA: Ras homolog gene family, member A.

lipid modifications, GTPase-activating proteins, and regulators of G-protein signaling ${ }^{[2]}$. These regulators could be important future drug discovery targets in GPCRs signaling. For example, in cancer therapy ${ }^{[20]}$.

Coupling of different GPCRs with different G-proteins families leads to cellular responses that control physiological functions. For instance, cellular growth and differentiation, metabolism, secretion, neurotransmission, inflammation, immune responses, vision, smell, and taste ${ }^{[9]}$. Therefore, disturbance in GPCRs signaling can lead to many diseases such as cancer, diabetes, and diseases of the central nervous system and cardiovascular system.

\section{GPCRs and Diseases}

G protein-coupled receptors targeted drugs are indicated for common chronic illnesses such as hypertension, obesity, diabetes, and asthma. They are also the targets for CNS disorders such as depression and schizophrenia. In addition, GPCRs have been studied as targets for multiple sclerosis and Alzheimer's disease. Other targeted indications include insomnia, osteoporosis, hypocalcemia, analgesia, short bowel syndrome, and smoking cessation. Furthermore, GPCRs as drug targets has been studied for cancer therapy ${ }^{[3]}$.

Since olfactory receptors are not only expressed in mouth and nose but also in tumor cells, targeting olfactory receptors could be a novel field in cancer therapy ${ }^{[4]}$. In addition, PARs have been linked to cancer invasion and metastasis. Thrombin and tissue factor, proteases that activate PAR1/3/4 and PAR2, respectively, are thought to be produced in a tumor environment regardless of blood coagulation. Thrombin/tissue factor-PARs signaling pathway may mediates metastasis by mechanisms, such as angiogenesis ${ }^{[21]}$.

There are a number of FDA-approved drugs targeting GPCRs used in cancer therapy, such as raloxifene and degarelix for the treatment of breast cancer and prostate cancer, respectively ${ }^{[21]}$. However, ligands for orphan GPCRs that are overexpressed in certain types of cancer are yet to be discovered, such as GRP161 in breast cancer and GPR49 in ovarian and colon cancer ${ }^{[22,23]}$.

\section{GPCRs as Drug Discovery Targets}

Drug targets can be divided into three groups, which are DNA transcription, RNA translation, and proteins targeted drugs ${ }^{[2]}$. G protein-coupled receptors are one of the classical drug targets that include ion channels, transporters, enzymes, and nuclearreceptors. Inaddition to classical drug targets, recombinant proteins and antibody-based therapy are under protein drug targets. Blocking mRNA translation is a novel drug targets that include technologies such as RNA interference and anti-sense oligonucleotide. Gene transcription can be targeted by modulation of transcription factors. Gene therapy, pharmacogenomics, cloning of drug targets, and transgenic mouse technology are all targeting the DNA $^{[2]}$.

G protein-coupled receptors are traditionally targeted with small molecules, less than 500 daltons, which are agonists or antagonists usually involving one mechanism of action, such as fentanyl, an opioid receptor agonist, and famotidine, a histamine $\mathrm{H} 2$ receptor antagonist ${ }^{[2,11]}$. Recently, new approaches for GPCR drug discovery have been developed such as allosteric modulators, biased agonism, polypharmacology, pharmacogenomics, and bitopic ligands ${ }^{[24]}$. These pharmacological approaches help in the advances of novel therapeutics GPCRs targets, with increased selectivity and minimized adverse effects.

\section{Approaches for GPCR Drug Discovery}

\section{GPCRs Polypharmacology}

Polypharmacology is a term given for ligands that interact with more than one target in the cell. Hauser 
et $a l_{.}^{[3]}$ found that there is an increase in the selectivity of GPCRs targeted drugs in current clinical trials. Thus, a decrease in polypharmacology ${ }^{[3]}$. Polypharmacology of drugs could be a disadvantage by causing adverse effects through acting on many targets. For example, the analgesic effect of morphine is due to $\mu$ receptorGi-protein pathway, while its side effects, such as respiratory depression, constipation, and tolerance, are due to $\beta$-arrestin pathway ${ }^{[25]}$. On the other hand, polypharmacology could be an advantage in other therapies ${ }^{[26]}$. For instance, donecopride, a multitarget-directed ligand, has been investigated as a potential drug for Alzheimer's disease by acting as an acetylcholinesterase inhibitor and a serotonin-5-HT4 agonist $^{[27]}$.

\section{Allosteric Modulators of GPCRs}

Other than targeting receptors by drugs binding to the orthostatic sites, a newer era in targeting GPCRs is using allosteric modulators that bind to sites other than the orthostatic sites of the biological ligands. Allosteric modulators are named positive allosteric modulators or negative allosteric modulators by enhancing or reducing the binding of ligands to their orthostatic sites, respectively. Fewer side effects, possible option for diseases with no effective therapy by modulating the effect of ligands rather than complete activation or inhibition are considered advantages of allosteric modulators $^{[28]}$.

Currently, there are two FDA-approved allosteric modulators of GPCRs. Cinacalcet, which is a positive allosteric modulator (PAM) on CaSRs for hyperparathyroidism and Maraviroc, which is a negative allosteric modulator (NAM) of the chemokine receptor 5 for HIV infection ${ }^{[29,30]}$. More recently, a PAM (3,4-dihydroisoquinolin-2(1H)-yl derivative) at dopamine D1 receptor has been invented to treat Parkinson's disease and schizophrenia ${ }^{[28]}$. Furthermore, this compound can potentially treat depression, attention deficit-hyperactivity disorder and Alzheimer's disease. On the other hand, the first NAM (SB269652) at dopamine D2 and D3 receptors may emerge a new class of antipsychotic drugs with higher selectivity ${ }^{[31]}$.

\section{GPCRs Biased Agonism}

Conventionally, GPCRs interaction with $\beta$-arrestin protein was known as a mechanism of receptor desensitization or downregulation. Recently, it has been found that the interaction of $\beta$-arrestin with a phosphorylated GPCR can also produce a signaling pathway. However, this pathway is G-protein independent ${ }^{[11,32]}$. This has opened a new paradigm in GPCRs drug discovery through biased agonism, which is also referred to as functional selectivity. Biased agonism is defined when a ligand prefers the activation of one of the signaling pathways, while another ligand prefers the activation of another pathway of the same receptor ${ }^{[33]}$.

Nebivolol and carvedilol, $\quad \beta$ blockers, are examples of biased agonists at $\beta$-arrestin that stimulate extracellular signal regulated kinase and the production of nitric oxide ${ }^{[11]}$. TRV120027, a biased ligand at $\beta$-arrestin, is a potential therapy for acute heart failure ${ }^{[34]}$. This novel drug is an octapeptide analog of angiotensin. However, unlike the action of angiotensin-Il type1 (AT1) receptor blockers through G-protein signaling pathway, TRV120027 action is through $\beta$-arrestin signaling, which decreases blood pressure, delays the development of heart failure, and produces cytoprotecting and antiapoptotic properties ${ }^{[19,35,36]}$. Thus, such agonist could be a promising discovery, where it stimulates the beneficial effects of Angiotensin-Il type-1 receptor $\beta$-arrestin pathway.

\section{Tethered Agonism}

Tethered agonism of GPCRs is defined as the activation of GPCRs indirectly by an internal ligand that is stimulated by a tethered agonist such as light, enzyme, and other ligands. Examples of GPCRs activated by tethered agonism include rhodopsin, PARs, adhesion GPCRs and glycoprotein hormone receptors that are activated by photon, proteases, mechanical forces, and ligand binding, respectively ${ }^{[18]}$.

A novel tethered ligand at PAR2, KVDGTS, has been identified in a study demonstrating that cathepsin $\mathrm{S}$ cleaves the N-terminus of PAR2. This cleavage was at a location near the cysteine proteases cleaving site exposing this novel tethered ligand ${ }^{[37]}$. Since PAR2 has been involved in inflammatory conditions and cathepsin S has been upregulated in inflammation, cathepsin S-PAR2 signal transduction pathway may be a promising area in drug discovery targets ${ }^{[38,39]}$.

\section{GPCRs Pharmacogenomics}

Genetic variation is a major cause of differences in drug response in each patient. Therefore, studying these 
genetic variations to develop personalized medicines, aiming to increase drug response and decrease adverse drug reactions, is an auspicious field in drug discovery targets. The number of missense variations in GPCR drug targets was approximately 60 per individual in a study investigated genome project of 2504 healthy subjects, where 8 variants were associated with known differences in drug response ${ }^{[40]}$. For instance, genetic polymorphism of dopamine DRD2 and DRD3 receptors is associated with gastrointestinal adverse effects in patients treated with levodopa ${ }^{[4]]}$.

It has been found that dopamine D5 receptors, calcitonin receptors, somatostatin 5 receptors, and cholecystokinin A receptors are the most GPCRs drug targets having genetic variations, where almost $40 \%$ of their known functional sites have amino acid variations ${ }^{[3]}$. Nonetheless, the prevalence and effects of genetic polymorphism of all FDA approved drugs targeting GPCRs are still to be revealed. Furthermore, labeling information of GPCRs targeting drugs does not include information about genetic variations ${ }^{[42]}$. Therefore, a tremendous amount of research is needed to treat patients with drugs according to their pharmacogenomic backgrounds.

\section{Tools for GPCRs Drug Discovery}

Structures of drug targets are needed to be illustrated for the discovery of novel therapeutics. G proteincoupled receptors are large transmembrane protein, for which the analysis using X-ray crystallography and nuclear magnetic resonance (NMR) spectroscopy is challenging, due to their structural instability in crystal form ${ }^{[2]}$. Despite this, the advancement in the technologies of protein engineering has improved the development of GPCRs crystallization.

Fusion proteins, site-directed mutagenesis, serial femtosecond crystallography, cryo-electron microscopy and in-meso crystallization using lipid cubic phase are examples of technologies used in studying GPCRs high resolution structures ${ }^{[43]}$. More than $40 \mathrm{GPCR}$ structures were identified between 2000 and 2016 $6^{[33]}$. Sensor-based screening of GPCR ligands is another emerging technique for GPCRs drug discovery ${ }^{[44]}$. These new methods are time and cost saving compared to the conventional high throughput screening of GPCRs. Together with the new pharmacological approaches, these methods may provide a tangible improvement in GPCRs research and therapy.

\section{Conclusion}

G protein-coupled receptors are one of the most significant drug discovery targets. This is because they are considered as the largest class of membrane receptors, and they account for almost one third of the FDA-targeted drugs and one third of global market sales of drugs. In addition, GPCRs have multiple ligands and complex signaling pathways that are involved in the physiology and pathophysiology of most body functions. Drugs targeting GPCRs are used to treat a wide range of diseases, such as chronic diseases, inflammatory diseases, and cancer. Furthermore, a large number of potential GPCRs drugs are in clinical trial, where novel strategies have been implemented in their discovery. Pharmacogenomics is likely to be the future trend in GPCRs targeted therapies. Moreover, new technologies could add a great advance in GPCRs research. All of these considerations including that only $10 \%$ of the known GPCRs are targeted make GPCRs continue to be chief targets in drug discovery.

\section{Conflict of Interest}

The author has no conflict of interest.

\section{Disclosure}

The author did not receive any type of commercial support either in forms of compensation or financial for this case report. The author has no financial interest in any of the products or devices, or drugs mentioned in this article.

\section{Ethical Approval}

Obtained.

\section{References}

[1] Katzung BG, Trevor AJ. Basic and Clinical Pharmacology. New York, NY: McGraw-Hill, 2015.

[2] Dickenson, J, Freeman F, Llyod Mills C, Sivasubramaniam S, Thode C. Molecular pharmacology from DNA to drug discovery. West Sussex, UK: Wiley Blackwell, 2013.

[3] Hauser AS, Chavali S, Masuho I, Jahn LJ, Martemyanov KA, Gloriam DE, Babu MM. Pharmacogenomics of GPCR drug targets. Cell 2018; 172(1-2): 41-54. e19.

[4] Foster SR, Roura E, Thomas WG. Extrasensory perception: odorant and taste receptors beyond the nose and mouth. Pharmacol Ther 2014; 142(1): 41-61. 
[5] Insel PA, Wilderman A, Zambon AC, Snead AN, Murray F, Aroonsakool N, McDonald DS, Zhou S, McCann T, Zhang L, Sriram K, Chinn AM, Michkov AV, Lynch RM, Overland AC, Corriden R. G Protein-coupled receptor (GPCR) expression in native cells: "Novel"endoGPCRs as physiologic pegulators and therapeutic targets. Mol Pharmacol 2015; 88(1): 181187.

[6] The IDG Knowledge Management Center. Unexplored opportunities in the druggable human genome. Nat Rev Drug Disc. Macmillan Publishers Limited. Accessed: $\quad<$ https://www.nature.com/nrd/posters/ druggablegenome/index.html>.

[7] Fang Y, Kenakin T, Liu C. Editorial: Orphan GPCRs As Emerging Drug Targets. Front Pharmacol 2015; 6: 295.

[8] [No authors listed]. Parsabiv (etelcalcetide) Injection. US Food and Drug Administration. Accessed on Feb. 7, 2017. $<$ https://www.accessdata.fda.gov/drugsatfda_docs/ nda/2017/2083250rig1s000TOC.cfm>

[9] Hu GM, Mai TL, Chen CM. Visualizing the GPCR Network: classification and evolution. Sci Rep 2017; 7(1): 15495

[10] Zhang XC, Liu J, Jiang D. Why is dimerization essential for class-C GPCR function? New insights from mGluR1 crystal structure analysis. Protein Cell 2014; 5(7): 492-495.

[11] Jacobson KA. New paradigms in GPCR drug discovery. Biochem Pharmacol 2015; 98(4): 541-555.

[12] Lane JR, Sexton PM, Christopoulos A. Bridging the gap: bitopic ligands of G-protein coupled-receptors. Trends Pharmacol Sci 2013; 34(1): 59-66.

[13] Jo E, Bhhatarai B, Repetto E, Guerrero M, Riley S, Brown SJ, Kohno Y, Roberts E, Schürer SC, Rosen H. Novel selective allosteric and bitopic ligands for the S1P3 receptor. ACS Chem Biol 2012; 7(12): 1975-1983.

[14] Harris GL, Creason MB, Brulte GB, Herr DR. In vitro and in vivo antagonism of a $G$ protein-coupled receptor (S1P3) with a novel blocking monoclonal antibody. PloS One 2012; 7(4): e35129.

[15] Thursby E, Juge N. Introduction to the human gut microbiota. Biochem J 2017: 474(11): 1823-1836.

[16] HuX,Wang T, Jin F. Alzheimer's diseases and gut microbiota. Sci China Life Sci 2016; 59(10): 1006-1023.

[17] Cohen LJ, Esterhazy D, Kim SH, Lemetre C, Aguilar RR, Gordon EA, Pickard AJ, Cross JR, Emiliano AB, Han SM, Chu J, Vila-Farres X, Kaplitt J, Rogoz A, Calle PY, Hunter C, Bitok JK, Brady SF. Commensal bacteria make GPCR ligands that mimic human signaling molecules. Nature 2017; 549(7670): 48-53.

[18] Schöneberg T, Kleinau G, Brüser A. What are they waiting for? Tethered agonism in G protein-coupled receptors. Pharmacol Res 2016; 108: 9-15.

[19] Lefkowitz, RJ. A brief history of G protein-coupled receptors (Nobel Lecture). Angew Chem Int Ed Engl 2013; 52(25): 6366-6378.
[20] Hurst JH, Hooks SB. Regulator of G-protein signaling proteins in cancer biology. Biochem Pharmacol 2009; 78(10): 1289-1297.

[21] Nieto Gutierrez A, McDonald PH GPCRs: Emerging anticancer drug targets. Cell Signal 2018; 41: 65-74.

[22] Feigin ME, Xue B, Hammell MC, Muthuswamy SK. G-protein-coupled receptor GPR161 is overexpressed in breast cancer and is a promoter of cell proliferation and invasion. Proc Natl Acad Sci U S A 2014; 111(11): 41914196.

[23] McClanahan T, Koseoglu S, Smith K, Grein J, Gustafson E, Black S, Kirschmeier P, Samatar AA. Identification of overexpression of orphan $G$ protein-coupled receptor GPR49 in human colon and ovarian primary tumors. Cancer Biol Ther 2006; 5(4): 419-426.

[24] Topiol S. Current and future challenges in GPCR drug discovery. Methods Mol 2018; 1705: 1-21.

[25] Raehal KM, Walker JK, Bohn LM. Morphine side effects in beta-arrestin 2 knockout mice. J Pharmacol Exp Ther 2005; 314(3): 1195-1201.

[26] Lavecchia A, Cerchia C. In silico methods to address polypharmacology: current status, applications and future perspectives. Drug Discov Today 2016; 21(2): 288-298.

[27] Rochais C, Lecoutey C, Gaven F, Giannoni P, Hamidouche K, Hedou D, Dubost E, Genest D, Yahiaoui S, Freret T, Bouet V, Dauphin F, Sopkova de Oliveira Santos J, Ballandonne C, Corvaisier S, Malzert-Fréon A, Legay R, Boulouard M, Claeysen S, Dallemagne P. Novel multitarget-directed ligands (MTDLs) with acetylcholinesterase (AChE) inhibitory and serotonergic subtype 4 receptor (5-HT4R) agonist activities as potential agents against Alzheimer's disease: the design of donecopride. J Med Chem 2015; 58(7): 3172-3187.

[28] Abdel-Majid AF. Allosteric modulators: an emerging concept in drug discovery. ACS Med Chem Lett 2015; 6(2): 104-107.

[29] [No authors listed]. Drug approval package. Sensipar (Cinacalcet HCl) Tablets. Approval dated March 8, 2004. Accessed <https://www.accessdata.fda.gov/drugsatfda_ docs/nda/2004/21-688_Sensipar.cfm>

[30] [No authors listed]. SELZENTRY (maraviroc) tablets. Initial U.S. Approval: 2007. Accessed: <https://www.accessdata. fda.gov/drugsatfda_docs/label/2007/022128lbl.pdf>

[31] Rossi M, Fasciani I, Marampon F, Maggio R, Scarselli M. The first negative allosteric modulator for dopamine $D_{2}$ and $D_{3}$ receptors, SB269652 may lead to a new generation of antipsychotic drugs. Mol Pharmacol 2017; 91 (6): 586-594.

[32] Rankovic Z, Brust TF, Bohn LM. Biased agonism: an emerging paradigm in GPCR drug discovery. Bioorg Med Chem Lett 2015; 26(2): 241-250.

[33] Patel CB, Noor N, Rockman HA. Functional selectivity in adrenergic and angiotensin signaling systems. Mol Pharmacol 2010; 78(6): 983-992. 
[34] Soergel D. A study to explore the efficacy of TRV027 in patients hospitalized for acute decompensated heart failure (BLAST-AHF). National Institute of Health. 2013. Accessed: <https://clinicaltrials.gov/ct2/show/NCT01966601>.

[35] Boerrigter G, Soergel DG, Violin JD, Lark MW, Burnett JC Jr. TRV120027, a Novel $\beta$-Arrestin biased ligand at the angiotensin I| type I receptor, unloads the heart and maintains renal function when added to furosemide in experimental heart failure. Cir Heart Fail 2012; 5(5): 627634.

[36] Boerrigter G, Lark MW, Whalen EJ, Soergel DG, Violin JD, Burnett JC Jr. Cardiorenal actions of TRV120027, a novel B-arrestin- biased ligand at the angiotensin II type | receptor, in healthy and heart failure canines: a novel therapeutic strategy for acute heart failure. Cir Heart Fail 2011; 4(6): 770-778

[37] Elmariah SB, Reddy VB, Lerner EA. Cathepsin S Signals via PAR2 and generates a novel tethered ligand receptor agonist. PLoS One 2014; 9(6): e99702.

[38] Moormann C, Artuc M, Pohl E, Varga G, Buddenkotte J, Vergnolle N, Brehler R, Henz BM, Schneider SW, Luger TA, Steinhoff $M$. Functional characterization and expression analysis of the proteinase-activated receptor-2 in human cutaneous mast cells. J Invest Dermatol 2006; 126(4): 746 755.

[39] Storm van's Gravesande K, Layne MD, Ye Q, Le L, Baron RM, Perrella MA, Santambrogio L, Silverman ES, Riese RJ. IFN regulatory factor-1 regulates IFN-gamma-dependent cathepsin s expression. J Immun 2002; 168(9): 4488-4494.

[40] 1000 Genomes Project Consortium, Auton A, Brooks LD, Durbin RM, Garrison EP, Kang HM, Korbel JO, Marchini JL, McCarthy S, McVean GA, Abecasis GR. A global reference for human genetic variation. Nature 2015; 526(7571): 6874.

[41] Rieck M, Schumacher-Schuh AF, Altmann V, CallegariJacques SM, Rieder CRM, Hutz MH. Association between DRD2 and DRD3 Gene polymorphisms and gastrointestinal symptoms induced by levodopa therapy in Parkinson's disease. Pharmacogenomics J 2018; 18(1): 196-200.

[42] Thompson, M.D. et al. (2014). Pharmacogenetics of the $G$ protein-coupled receptors. In: Pharmacogenomics in Drug Discovery and Development. Methods in Molecular Biology (Methods and Protocols): Yan Q. (eds). New York, NY: Humana Press. vol 1175

[43] Xiang J, Chun E, Liu C, Jing L, Al-Sahouri Z, Zhu L, Liu $W$. Successful strategies to determine high-resolution structures of GPCRs. Trends Pharmacol Sci 2016; 37(12): 1055-1069.

[44] Kumari P, Ghosh E, Shukla AK. Emerging approaches to GPCR ligand screening for drug discovery. Trends Mol Med 2015; $21(11):$ 687-701. 


\section{بإسرى صالح أندابماني}

\section{قسم علم الأدوية والسموم ، كلية الصيدلة ، جامعة طيبة \\ الدينة الدنورة ، الدملكة العربية السعودية السية كلية العية}

المستخطص. تعتبر المستقبلات المرتبطة بالبروتين ج من أكثر المستقبلات استهدافا في اكتشاف الأدوية ، حيث تعتبر من أكثر المستقبلات

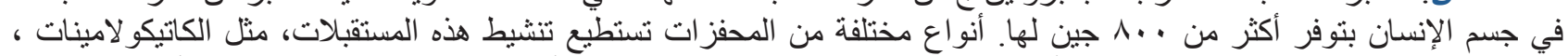

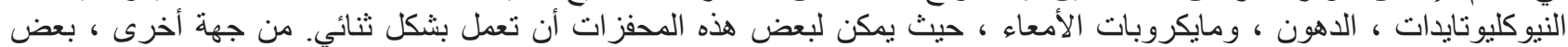

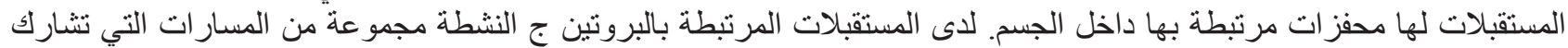

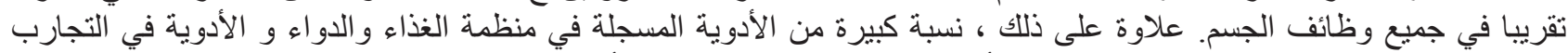

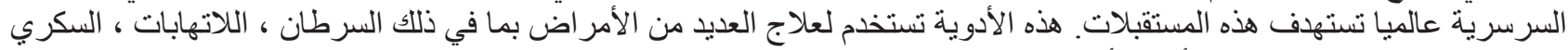

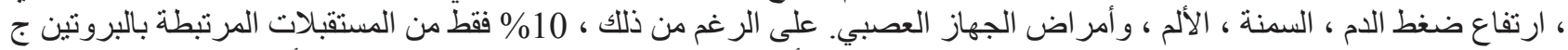

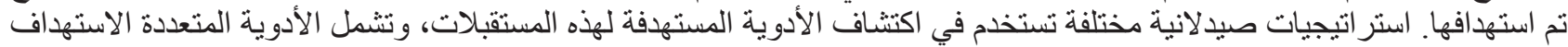

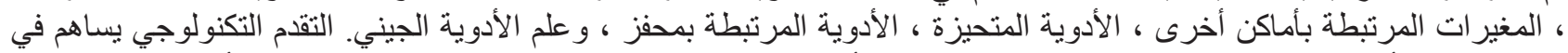

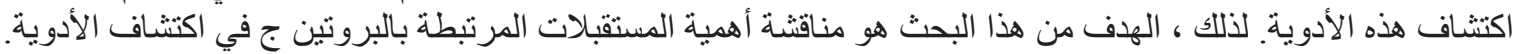

